\title{
A percepção de servidores universitários sobre as políticas, ações e discursos institucionais sobre o assédio moral no trabalho
}

\section{The perception of university employees' on institutional policies, actions and discussions about workplace bullying}

\author{
THIAGO SOARES NUNES* \\ SUZANA DA ROSA TOLFO** \\ LEONOR MARÍA CANTERA ESPINOSA***
}

\section{RESUMO}

O artigo objetiva descrever a percepção dos servidores docentes e técnico-administrativos de uma universidade federal, localizada na região Sul brasileira, em relação às práticas e discursos organizacionais sobre o assédio moral no trabalho. A pesquisa classificou-se como qualitativa e descritiva. A coleta dos dados ocorreu pela aplicação de um questionário online, divulgado por e-mail, respondido por 214 servidores, bem como pela realização de 12 entrevistas. O exame de dados utilizou a análise de conteúdo. Constatou-se que a universidade não demonstra claramente suas políticas e ações em relação ao assédio, o que inflencia na sua prática ou denúncia interna. Além disto, como forma de prevenir e combater a violência, os participantes sugerem tanto aspectos individuais, que têm relação com o comportamento

* Centro Universitário UNA. Professor do Mestrado Profissional em Administração do Centro Universitário UNA. Doutor em Administração pela Universidade Federal de Santa Catarina (UFSC). adm.thiagosn@gmail.com

** Universidade Federal de Santa Catarina (UFSC). Professora do Programa de Pós-Graduação em Psicologia da UFSC. Doutora em Administração pela Universidade Federal de Rio Grande do Sul (UFRGS). srtolfo14@gmail.com

*** Universitat Autònoma de Barcelona (UAB). Professora do Programa de Pós-Graduação em Psicologia Social da UAB. Doutora em Psicologia pela Universidade de Porto Rico (UPR). leonor.cantera@uab.cat 
e ações no trabalho (a prática do código de ética, respeitar e valorizar o outro), quanto institucionais, que trazem elementos presentes na cultura e nas práticas organizacionais (formação das chefias, aplicação e controle do código de ética profissional do servidor público, mudança cultural, criação de comissões, maior divulgação sobre o assédio, gestão mais técnica). Portanto, trazem elementos de prevenção que vão além de estratégias exclusivas sobre o assédio, como práticas saudáveis e éticas no ambiente laboral e nas relações interpessoais.

Palavras-chave: Assédio moral no trabalho; Universidade; Servidores.

\section{Abstract}

The article aims to describe the perception of professors and technical-administrative employees of a federal university, located in the southern region of Brazil, in relation to organizational practices and discourses about workplace bullying. The research was classified as qualitative with a descriptive approach. Data collection ocurred by the application of an online questionnaire, disseminated by e-mail, answered by 214 employees, and was conducted 12 interviews. Data was analyzed through content analysis approach. It was found that the university doesn't clearly demonstrates its policies and actions in relation to workplace bullying, which influence on their practice or internal complaint. In addition, to prevent and combat the bullying, the participants suggest individual aspects, which are related to behavior and actions at work (the practice of the code of ethics, respect and value the other), and institutional aspects, which bring elements presents in the culture and organizational practices (management training, application and control of the code of professional ethics of public servants, cultural change, creation of commissions, greater dissemination on harassment, more technical management). Therefore, they bring prevention elements that go beyond exclusive strategies on bullying, but rather healthy and ethical practices in the workplace and in interpersonal relationships. Keywords: Workplace bullying; University; Public Employee. 


\section{INTRODUÇÃo}

As organizações definem, de forma explícita ou implícita, por meio de sua cultura, determinados padrões de relacionamento e estrutura (formal e informal) e principalmente os seus valores (FREITAS; HELOANI; BARRETO, 2008). No entanto, ao mesmo tempo em que ela estabelecem um discurso de cooperação e trabalho em equipe enfatizam a competição pela aquisição e manutenção de um posto de trabalho (HELOANI, 2005). Nessa disputa o individualismo, o medo de perder o poder/cargo, o "atropelamento da ética", o alcance dos objetivos-fim sem se preocupar com os meios e a aceitação do "trabalho sujo" se tornam estratégias de ação, as quais demonstram a existência de um problema estrutural, cultural e comportamental na sociedade, na organização e no próprio indivíduo (DEJOURS, 2007; HELOANI, 2005).

Todas estas práticas e comportamentos antiéticos e desrespeitosos são vivenciados e praticados pelos gestores e/ou trabalhadores cotidianamente nos seus ambientes de trabalho, e muitos estão inseridos na própria cultura das instituições. Esses tipos de postura podem favorecer e incitar relações de violência, de humilhação, de exclusão, ou seja, de assédio moral no trabalho. A violência moral é um fenômeno tão antigo quanto o próprio trabalho. No entanto, ganhou maior visibilidade como fator desencadeador de sofrimento no trabalho principalmente devido à flexibilização das relações trabalhistas e às mudanças no mundo do trabalho (NUNES; TOLFO, 2015).

O assédio moral pode ser definido como comportamento, ações e práticas hostis repetidamente dirigidas a um ou mais trabalhadores de forma consciente ou inconsciente e que podem trazer danos à integridade psíquica ou física do indivíduo, além de interferir no desempenho e no ambiente de trabalho (EINARSEN et al., 2005). Por ocorrer dentro do ambiente laboral, torna-se um problema organizacional e assim sendo a organização é corresponsável pela sua prática ou pela isenção dos comportamentos e estratégias hostis (NUNES; TOLFO, 2013a).

Estudar e intervir nesse fenômeno complexo implica em considerar diversos aspectos que o constituem, tais como psicológicos, interpessoais, organizacionais, legais e ambientais (TOLFO; NUNES; EMMENDOERFER, 2015). Em outras palavras, as organizações 
devem (ou deveriam) desenvolver mecanismos de prevenção e combate que atuem principalmente nessas áreas. No entanto, o que se constata comumente é o descaso de instituições e gestores com o trabalhador e com os aspectos situacionais que podem provocar a violência - uma vez que muitas seguem a lógica segundo a qual quando os resultados são alcançados não importam o modo como foi realizado ou as estratégias adotadas (NUNES; TOLFO, 2012b).

Ao contextualizar o assédio moral no ambiente universitário/ educacional é possível constatar na literatura que este meio é um dos mais afetados pela violência (HIRIGOYEN, 2006; NUNES; TOLFO, 2012b; 2015). A universidade, que deveria primar por ambientes saudáveis para seus usuários e trabalhadores, muitas vezes é conivente com práticas hostis e violentas, e pouco (ou raramente) realiza ações interventivas ou de prevenção/combate para cessar/amenizar a prática do assédio moral (NUNES; TOLFO, 2012b). Deixa desta forma as vítimas - os seus trabalhadores - desamparadas e sem suporte algum para se recuperarem das vivencias negativas que sofrem no ambiente laboral. Esse cenário despertou o interesse de produzir este artigo, que tem por objetivo descrever a percepção dos servidores docentes e técnico-administrativos de uma universidade federal, localizada na região Sul brasileira, em relação às práticas e discursos organizacionais sobre o assédio moral no trabalho.

O trabalho ora apresentado revela-se como uma importante contribuição para o desenvolvimento do tema. Note-se que, além de revelar as práticas e discursos organizacionais acerca do assédio moral, tem como base a percepção dos participantes da pesquisa e destaca que não somente medidas diretas sobre assédio moral devem ser tomadas para prevenir e combater a violência. É necessário focar também em aspectos individuais e institucionais, como a prática de código de ética, respeito e valorização do outro, formação de chefias, gestões técnicas e demais. Tais aspectos são buscados por todas instituições, públicas ou privadas, das mais diversas áreas. Portanto, discutir sobre as práticas organizacionais acerca do assédio moral é pertinente, dada a realidade vivenciada pelo trabalhador no âmbito laboral, na qual a violência se torna cada vez mais presente - afetando não somente a saúde e o trabalho do indivíduo, mas inclusive a própria organização. 
Este artigo está estruturado em cinco partes a contar desta introdução. A seção seguinte trata do referencial teórico sobre assédio moral no trabalho, entrando especialmente na questão sobre prevenção e combate. Em seguida é exposto o método utilizado para a condução desta pesquisa. A quarta seção se refere à apresentação e análise dos resultados e, por último, as considerações finais do estudo.

\section{AsSÉdio Moral No TRABALHO}

Abordar o assédio moral no trabalho implica em reconhecer que este faz parte do debate sobre a violência. Tratar de violência é abordar um fenômeno complexo - atravessado por diversos outros fenômenos. Embora seja difícil de ser conceituada, compreende-se a violência como "qualquer tipo de comportamento agressivo ou abusivo que possa causar um dano ou desconforto físico ou psicológico em suas vítimas, sejam esses alvos intencionais ou envolvidos de forma impessoal ou incidental" (WARSHAW, 1998, p. 51-52).

$\mathrm{O}$ assédio moral no trabalho implica em qualquer conduta abusiva (atitudes, comportamentos, palavras, ações, gestos, escritos) que, por repetição, podem trazer danos à personalidade, à dignidade ou à integridade física ou psíquica da vítima, além de alterar o ambiente psicossocial de trabalho (HIRIGOYEN, 2006). O conceito anterior demonstra que a natureza dos comportamentos hostis pode ser diversa. Muitas vezes essas condutas são oriundas do abuso de poder, por vingança, percepção de características (físicas ou comportamentais) indesejadas da vítima, recusa de uma diferença ou de outros elementos (MATHISEN; EINARSEN; MYKLETUN, 2011; NUNES; TOLFO; NUNES, 2013).

Embora os conceitos sobre o tema sejam similares e até complementares (NUNES; TOLFO, 2015), existem elementos distintivos que auxiliam a caracterizar o fenômeno, entre os quais destacamos: frequência e duração. O assédio não se subtende a eventos isolados, mas em comportamentos repetidos e persistentes (LEYMANN, 1990; EINARSEN et al., 2005; 2011; FREITAS; HELOANI; BARRETO; 2008). Barreto (2005) relata que na sua pesquisa com trabalhadores brasileiros a duração dos comportamentos hostis variou de 3 meses a mais de 3 anos, dependendo do tipo de empresa (privada ou pública).

Por sua vez, é fundamental identificar e conhecer as situações 
hostis para evitá-las. As principais práticas de assédio moral podem ser agrupadas em quatro subgrupos, que correspondem a situações das mais sutis e difíceis de serem identificadas até às mais evidentes e visíveis (HIRIGOYEN, 2006). Segundo a autora, são elas: a) Deterioração proposital das condições de trabalho: agir de maneira a fazer a vítima parecer incompetente, como contestar sistematicamente as decisões por ela tomadas, críticas exageradas e injustas em relação ao seu trabalho, induzir o alvo ao erro, instruções impossíveis de serem seguidas, entre outras; b) Isolamento e recusa de comunicação: comportamentos com intuito de constranger e maltratar o outro, tais como deixar alguém de fora de uma conversa, recusar-se a falar-lhe, não convidá-lo para reuniões, interromper a pessoa constantemente, comunicar com a pessoa somente por escrito, evitar contato (até visual), e outros; c) Atentado contra a dignidade: gestos de desprezo, chacotas e insinuações desqualificadas que são geralmente reparados por todos, entretanto, a vítima é considerada responsável. Nesse caso o agressor utiliza-se de insinuações desdenhosas para desqualificar a vítima, criticar sua vida pessoal, zombando de suas origens, nacionalidades e outros; d) Violência verbal, física ou sexual: aparece quando o assédio está declarado e visível a todos. Nesta categoria acontecem as ameaças de violência física, empurrões, gritos injuriosos, assédio sexual, impertinência que se prolonga também para fora do ambiente organizacional, com telefonemas noturnos e cartas anônimas, por exemplo (HIRIGOYEN, 2006). Constam nas definições e descrições sobre assédio moral uma significativa variedade de comportamentos hostis, sejam elas situações físicas, verbais ou comportamentais que atuam diretamente para a personalidade do alvo ou para as atividades por ele desenvolvida no ambiente de trabalho (SKOGSTAD et al., 2011).

As situações hostis vivenciadas pelas vítimas podem provocar severos efeitos e consequências, seja no âmbito de sua saúde (física e/ou psíquica) e até mesmo na própria organização, no ambiente laboral (HOEL; SPARKS; COOPER, 2001; HIRIGOYEN, 2006; NUNES; TOLFO, 2012a). Algumas das implicações que podem surgir na saúde da vítima são: abandono das relações pessoais, alteração no sono, aumento da pressão arterial, cefaleia, consumo excessivo de álcool e outras drogas, descontentamento com o trabalho, dificuldade de concentração, dores generalizadas e esporádicas, enjoos, falta de apetite, insegurança, manifestações depressivas, raiva, ten- 
sões musculares, vontade de chorar por tudo, e em alguns casos, o suicídio (HOEL; SPARKS; COOPER, 2001; KEASHLY; JAGATIC, 2003; BARRETO, 2006; NUNES; TOLFO, 2012a).

Já os efeitos para a organização e ambiente laboral podem ser: absenteísmo, aposentadoria prematura, aumento dos custos devido às ausências, enfraquecimento da adesão ao projeto organizacional, eventual redução do valor da marca, exposição negativa da organização, redução da produtividade e desempenho, rotatividade de pessoal, clima conflituoso, problemas de relacionamento interpessoal, e outros (HOEL; SPARKS; COOPER, 2001; HOEL; EINARSEN; COOPER, 2003).

O assédio moral não é uma brincadeira; é uma situação grave que pode trazer severos danos para o indivíduo assediado e efeitos para a própria organização. Por essa violência ocorrer no âmbito laboral, as instituições e seus gestores têm papel fundamental - a sua prevenção e combate (NUNES; TOLFO, 2012b; 2013b). Ao considerar o assédio moral como um aspecto organizacional é importante compreender que algumas organizações negligenciam "[...] os aspectos desencadeadores desse fenômeno, ou seja, consideramos que o assédio moral ocorra não porque os dirigentes o desejem, mas porque eles se omitem" (FREITAS; HELOANI; BARRETO, 2008, p. 38). Desta forma, para reduzir os casos de assédio moral é preciso coibir os fatores que possam provocar tais comportamentos e ações hostis, abordar, esclarecer melhor sobre o tema e as consequências para o agressor e principalmente desenvolver e aplicar políticas e ações de prevenção, intervenção e combate (SALIN, 2008; EINARSEN; HOEL, 2008; NUNES; CUGNIER; TOLFO, 2015).

As respostas da organização em relação à ocorrência de assédio moral podem ocorrer de duas formas: a) prevenção, que envolve a construção de uma nova mentalidade no ambiente laboral; b) combate, que remete ao presente imediato e tem a intenção de construir instrumentos e mecanismos de controle e punição pelas práticas hostis (TOLFO et al., 2016). Em pesquisas realizadas por Pinheiro e Tolfo (2010) e Fabro e Tolfo (2011) em relação ao que tem sido feito ou proposto como ações contra o assédio em periódicos e eventos, livros, banco de teses e dissertações, bem como outros materiais sobre o tema, foram identificadas: ações de diagnóstico e investigação organizacional do assédio moral; estratégias de prevenção; estratégias de intervenção. Tais itens podem ser visualizados nos quadros a seguir, das mais para as menos citadas. 
Quadro 1: Propostas de diagnóstico organizacional

\begin{tabular}{|l|l|l|}
\hline \multicolumn{2}{|l}{ DIAGNÓSTICO ORGANIZACIONAL } & FREQ. \\
\hline ITENS (N=11) & AUTOR(ES) & 5 \\
\hline $\begin{array}{l}\text { Avaliar os fatores de riscos } \\
\text { psicossociais. }\end{array}$ & $\begin{array}{l}\text { European Agency for Safety and } \\
\text { Health at Work (2002), Luna } \\
\text { (2003), Tehrani (2005), Rendon } \\
\text { (2005), Guimarães; Rimoli (2006). }\end{array}$ & 2 \\
\hline $\begin{array}{l}\text { Refletir sobre a forma de } \\
\text { organização de trabalho e } \\
\text { seus métodos de gestão de } \\
\text { pessoal. }\end{array}$ & $\begin{array}{l}\text { Zimmermann; Santos; Lima } \\
\text { (2002), Tarcitano; Guimarães } \\
\text { (2004). }\end{array}$ & 2 \\
\hline $\begin{array}{l}\text { Refletir acerca das práticas } \\
\text { organizacionais e da cultura } \\
\text { organizacional, averiguando } \\
\text { possibilidades de mudanças. }\end{array}$ & Bradaschia (2007), Felippe (2007). & 2 \\
\hline $\begin{array}{l}\text { Realizar pesquisas com os } \\
\text { funcionários. }\end{array}$ & $\begin{array}{l}\text { Beswick; Gore; Palferman (2006); } \\
\text { Salin (2008). }\end{array}$ & 2 \\
\hline $\begin{array}{l}\text { Verificar o ambiente e acom- } \\
\text { panhar a equipe. }\end{array}$ & Salin (2008). & 1 \\
\hline $\begin{array}{l}\text { Realizar discussões formais } \\
\text { e informais da avaliação } \\
\text { com os funcionários. }\end{array}$ & Salin (2008). & 1 \\
\hline $\begin{array}{l}\text { Acompanhar o absenteísmo, } \\
\text { as reclamações e as faltas } \\
\text { por doença. }\end{array}$ & Beswick; Gore; Palferman (2006). & 1 \\
\hline $\begin{array}{l}\text { Utilizar medidas psicomé- } \\
\text { tricas como forma de diag- } \\
\text { nosticar assédio moral no } \\
\text { trabalho. }\end{array}$ & Beswick; Gore; Palferman (2006). & 1 \\
\hline $\begin{array}{l}\text { Investigar a dimensão e } \\
\text { natureza do problema. }\end{array}$ & European Agency for Safety and \\
\hline $\begin{array}{l}\text { Realizar pesquisa sobre o } \\
\text { clima organizacional. }\end{array}$ & Xavier (2010). & 1 \\
\hline Avaliar a forma de gestão. & Elgenneni (2007). & 1 \\
\hline
\end{tabular}

Fonte: adaptado de Pinheiro e Tolfo (2010) e Fabro e Tolfo (2011). 
É possível observar que o quadro anterior apresenta poucas propostas de diagnóstico organizacional, ao contrário das sugestões de prevenção e intervenção que são frequentemente mencionadas isso pressupõe que autores e pesquisadores têm pouco interesse em identificar situações e práticas organizacionais que possam propiciar ou favorecer ações de assédio moral. Para Tolfo et al. (2016, p. 273), "os riscos psicossociais associados ao trabalho, às condições de trabalho, à organização do trabalho e ao reconhecimento da existência do assédio moral são aspectos relevantes para considerar a identificação do problema". Os riscos psicossociais podem ser compreendidos como agentes ou fatores de riscos, que estão presentes no ambiente laboral, que alteram a situação de bem-estar dos trabalhadores, e com isso podem provocar efeitos à saúde (física ou psíquica) do trabalhador (CARAN, 2007).

\section{Quadro 2: Propostas de prevenção}

\begin{tabular}{|c|c|c|}
\hline \multicolumn{3}{|l|}{ PREVENÇÃO } \\
\hline ITENS $(\mathrm{N}=12)$ & AUTOR(ES) & FREQ \\
\hline $\begin{array}{l}\text { Promover mu- } \\
\text { danças na cultura } \\
\text { organizacional. }\end{array}$ & $\begin{array}{l}\text { Vega (2002); Luna (2003); Piñuel y Zabala (2003); } \\
\text { Scanfone; Teodósio (2004); Tarcitano; Guimarães } \\
\text { (2004); Leclerc (2005); Tehrani (2005); Beswick; Gore; } \\
\text { Palferman (2006); Hoel; Giga (2006); Guimarães; } \\
\text { Rimoli (2006); Bradaschia (2007); Terrin; Oliveira } \\
\text { (2007); Felippe (2007); Aguiar (2008); Xavier (2010). }\end{array}$ & 16 \\
\hline $\begin{array}{l}\text { Educar e capacitar } \\
\text { gerentes, pessoas- } \\
\text { chave e líderes. }\end{array}$ & $\begin{array}{l}\text { European Agency for Safety and Health at Work } \\
\text { (2002); Zimmermann; Santos; Lima (2002); Luna } \\
\text { (2003); Piñuel y Zabala (2003); Rendon (2005); Tehra- } \\
\text { ni (2005); Beswick; Gore; Palferman (2006); Terrin; } \\
\text { Oliveira (2007); Elgenneni (2007); Aguiar (2008); Salin } \\
\text { (2008); Mussi; Oliveira (2008); Martiningo Filho; Si- } \\
\text { queira (2008); Amazarray (2010); Xavier (2010). }\end{array}$ & 15 \\
\hline $\begin{array}{l}\text { Criar um códi- } \\
\text { go de conduta/ } \\
\text { código de ética, } \\
\text { incluir normas de } \\
\text { conduta. }\end{array}$ & $\begin{array}{l}\text { European Agency for Safety and Health at Work (2002); } \\
\text { Zimmermann; Santos; Lima (2002); Einarsen et al. (2003); } \\
\text { Luna (2003); Tarcitano; Guimarães (2004); Einarsen } \\
\text { (2005); Hirigoyen (2005); Rendon (2005); Tehrani (2005); } \\
\text { Leclerc (2005); Beswick; Gore; Palferman (2006); Terrin; } \\
\text { Oliveira (2007); Elgenneni (2007); Aguiar (2008); Avila } \\
\text { (2008); Salin (2008); Mussi; Oliveira (2008); Martiningo } \\
\text { Filho; Siqueira (2008); Xavier (2010). }\end{array}$ & 15 \\
\hline
\end{tabular}




\begin{tabular}{|c|c|c|}
\hline \multicolumn{3}{|l|}{ PREVENÇÃO } \\
\hline ITENS $(\mathrm{N}=12)$ & AUTOR(ES) & FREQ. \\
\hline $\begin{array}{l}\text { Promover práticas } \\
\text { que estimulem o } \\
\text { respeito, a cola- } \\
\text { boração e a inte- } \\
\text { gração entre os } \\
\text { funcionários. }\end{array}$ & $\begin{array}{l}\text { European Agency for Safety and Health at Work } \\
\text { (2002); Luna (2003); Piñuel y Zabala (2003); Scanfone; } \\
\text { Teodósio (2004); Rendon (2005); Tehrani (2005); Hiri- } \\
\text { goyen (2005); Guimarães; Rimoli (2006); } \\
\text { Elgenneni (2007); Bradaschia (2007); Avila (2008); } \\
\text { Mussi; Oliveira (2008); Martiningo Filho; Siqueira } \\
\text { (2008); Amazarray (2010); Xavier (2010). }\end{array}$ & 15 \\
\hline $\begin{array}{l}\text { Conscientizar e } \\
\text { disseminar in- } \\
\text { formações sobre } \\
\text { assédio }\end{array}$ & $\begin{array}{l}\text { European Agency for Safety and Health at Work (2002); } \\
\text { Zimmermann; Santos; Lima (2002); Luna (2003); Tar- } \\
\text { citano; Guimarães (2004); Hirigoyen (2005); Leclerc } \\
\text { (2005); Beswick; Gore; Palferman (2006); Bradaschia } \\
\text { (2007); Felippe (2007); Aguiar (2008); Avila (2008); Salin } \\
\text { (2008); Amazarray (2010); Xavier (2010). }\end{array}$ & 14 \\
\hline $\begin{array}{l}\text { Educar e capacitar } \\
\text { os funcionários. }\end{array}$ & $\begin{array}{l}\text { Piñuel Y Zabala (2003); Tarcitano; Guimarães (2004); } \\
\text { Hirigoyen (2005); Rendon (2005); Tehrani (2005); Le- } \\
\text { clerc (2005); Beswick; Gore; Palferman (2006); Elgen- } \\
\text { neni (2007). }\end{array}$ & 8 \\
\hline $\begin{array}{l}\text { Desenvolver co- } \\
\text { municação interna, } \\
\text { promover o diá- } \\
\text { logo, grupos de } \\
\text { debate, espaços de } \\
\text { escuta. }\end{array}$ & $\begin{array}{l}\text { Zimmermann; Santos; Lima (2002); Piñuel y Zabala } \\
\text { (2003); Hirigoyen (2005); Martiningo Filho; Siqueira } \\
\text { (2008); Aguiar (2008); Xavier (2010). }\end{array}$ & 6 \\
\hline Reduzir o estresse. & $\begin{array}{l}\text { Luna (2003); Piñuel Y Zabala (2003); Hirigoyen } \\
\text { (2005); Aguiar (2008); Mussi; Oliveira (2008). }\end{array}$ & 5 \\
\hline $\begin{array}{l}\text { Criar ambiente de } \\
\text { trabalho saudável; } \\
\text { melhorar as condi- } \\
\text { ções de trabalho e } \\
\text { garantir qualidade } \\
\text { de vida no trabalho. }\end{array}$ & $\begin{array}{l}\text { Piñuel y Zabala (2003); Rendon (2005); Hirigoyen } \\
\text { (2005); Guimarães; Rimoli (2006); Terrin; Oliveira } \\
\text { (2007). }\end{array}$ & 5 \\
\hline
\end{tabular}




\begin{tabular}{|l|l|l|}
\hline \multicolumn{2}{|l|}{ PREVENÇÃO } & FUTOR(ES) \\
\hline ITENS (N=12) & \\
\hline $\begin{array}{l}\text { Possibilitar auto- } \\
\text { nomia para orga- } \\
\text { nizar o trabalho, } \\
\text { fornecer informa- } \\
\text { ções e recursos } \\
\text { necessários para } \\
\begin{array}{l}\text { a execução das } \\
\text { tarefas e reduzir o } \\
\text { trabalho monótono } \\
\text { e repetitivo. }\end{array}\end{array}$ & $\begin{array}{l}\text { European Agency for Safety and Health at Work } \\
\text { (2002); Luna (2003); Piñuel y Zabala (2003); Tarcita- } \\
\text { no; Guimarães (2004); Rendon (2005). }\end{array}$ & 5 \\
\hline $\begin{array}{l}\text { Aumentar a fiscali- } \\
\text { zação/controle dos } \\
\text { funcionários }\end{array}$ & $\begin{array}{l}\text { Luna (2003); Mussi; Oliveira (2008); Avila (2008); } \\
\text { Amazarray (2010). }\end{array}$ & 4 \\
\hline $\begin{array}{l}\text { Dar exemplo de } \\
\text { comportamento e/ } \\
\text { ou conduta ade- } \\
\text { quada e promover } \\
\text { mudanças na orga- } \\
\text { nização que com- } \\
\text { batam ao assédio }\end{array}$ & $\begin{array}{l}\text { Hirigoyen (2005); Beswick; Gore; Palferman (2006); } \\
\text { Bradaschia (2007). }\end{array}$ & 3 \\
\hline
\end{tabular}

Fonte: adaptado de Pinheiro e Tolfo (2010) e Fabro e Tolfo (2011)

As propostas de prevenção apresentadas pelos autores refletem estratégias para coibir a prática e evitar que a violência seja naturalizada no ambiente laboral. Um dos fatores preponderantes para a ocorrência do assédio moral é a própria cultura organizacional. Para Salin (2003) o assédio moral pode ser visto como parte da cultura da organização, de modo que a sua ocorrência é aceita como forma de alcançar a atividade imposta. Na perspectiva de Nunes e Tolfo (2013a), em organizações onde existe uma racionalidade instrumental - na qual os fins justificam os meios - os agressores se tornam inatingíveis pois muitas vezes conseguem alcançar/ultrapassar suas metas. Ou seja, o assédio moral se torna uma "ferramenta administrativa" eficaz para a realização do trabalho. "O fato de que a transmissão da cultura se dá basicamente de forma inconsciente e inquestionável explica, em parte, porque as empresas punem comportamentos 
desejados e recompensam aqueles indesejáveis" (ZIEMER, 1996, p. 125). Ao analisarem essa questão, Freitas, Heloani e Barreto (2008, p. 109) defendem que "erradicar a cultura da impunidade, da falta de respeito, da promiscuidade e da indigência moral no ambiente de trabalho é tarefa coletiva, que precisa da cooperação dos ocupantes de cargos mais elevados".

Por sua vez, alguns estudiosos entendem que identificar o que pode ter causado o assédio moral é menos importante do que cessar as situações hostis (EINARSEN; HOEL, 2008). Para os autores existem alguns elementos que devem estar presentes nos métodos de prevenção: criação de um clima social com atmosfera aberta e respeitosa, com tolerância a diversidade, onde a existência de frustração e atrito é aceita, mas também propriamente administrada; garantia de que os estilos de liderança e práticas administrativas na organização são aplicados a todos os funcionários de forma igualitária, garantindo tratamento justo e com respeito e que a sensibilidade para necessidades pessoais e vulnerabilidades seja levada em conta. Outros destaques: garantia de que os gestores tenham treinamento e capacidade para administrar conflitos e de que a instituição tenha metas, regras e responsabilidades claras e nítidas, bem como ética de trabalho; criação e manutenção de uma cultura organizacional em que o assédio moral e os maus tratos aos funcionários não sejam tolerados. 


\section{Quadro 3: Propostas de intervenção}

\begin{tabular}{|c|c|c|}
\hline \multicolumn{3}{|l|}{ INTERVENÇÃO } \\
\hline ITENS $(\mathrm{N}=12)$ & AUTOR(ES) & FREQ. \\
\hline $\begin{array}{l}\text { Criar espaço de confiança } \\
\text { dentro da empresa (comitês, } \\
\text { canais de escuta) para que o } \\
\text { trabalhador possa expressar } \\
\text { suas queixas. }\end{array}$ & $\begin{array}{l}\text { Zimmermann; Santos; Lima } \\
\text { (2002); Scanfone; Teodósio (2004); } \\
\text { Tarcitano; Guimarães (2004); } \\
\text { Rendon (2005); Hirigoyen (2005); } \\
\text { Aguiar (2008); Amazarray (2010); } \\
\text { Xavier (2010). }\end{array}$ & 8 \\
\hline $\begin{array}{l}\text { Estabelecer um terceiro im- } \\
\text { parcial (mediador) dentro da } \\
\text { empresa. }\end{array}$ & $\begin{array}{l}\text { Luna (2003); Leclerc (2005); } \\
\text { Tehrani (2005); Leclerc (2005); } \\
\text { Beswick; Gore; Palferman (2006); } \\
\text { Oliveira (2007); Elgenneni (2007); } \\
\text { Aguiar (2008); Martiningo Filho; } \\
\text { Siqueira (2008). }\end{array}$ & 8 \\
\hline $\begin{array}{l}\text { Aplicar medidas disciplinares } \\
\text { e/ou sanções aos agressores e } \\
\text { empregadores. }\end{array}$ & $\begin{array}{l}\text { Zimmermann; Santos; Lima } \\
\text { (2002); Luna (2003); Leclerc } \\
\text { (2005); Beswick; Gore; Palferman } \\
\text { (2006); Martiningo Filho; Siqueira } \\
\text { (2008). }\end{array}$ & 5 \\
\hline $\begin{array}{l}\text { Identificar e avaliar uma } \\
\text { situação de assédio moral, } \\
\text { buscando intervir de forma } \\
\text { contextualizada e de acordo } \\
\text { com a fase na qual a situação } \\
\text { se encontra. }\end{array}$ & $\begin{array}{l}\text { Zimmermann; Santos; Lima } \\
\text { (2002); Vega (2002); Rendon } \\
\text { (2005); } \\
\text { Hoel; Giga (2006); Martiningo } \\
\text { Filho; Siqueira (2008). }\end{array}$ & 5 \\
\hline $\begin{array}{l}\text { Proteger judicialmente a } \\
\text { vítima. }\end{array}$ & $\begin{array}{l}\text { Leclerc (2005); Rendon (2005); } \\
\text { Bradaschia (2007); Avila (2008); } \\
\text { Mussi; Oliveira (2008). }\end{array}$ & 5 \\
\hline $\begin{array}{l}\text { Minimizar as consequências } \\
\text { para a vítima (fornecer apoio } \\
\text { psicológico, definir estratégia } \\
\text { terapêutica, práticas alternati- } \\
\text { vas, conscientização grupal). }\end{array}$ & $\begin{array}{l}\text { Vega (2002); Zimmermann; } \\
\text { Santos; Lima (2002); Guimarães; } \\
\text { Rimoli (2006); Elgenneni (2007). }\end{array}$ & 4 \\
\hline $\begin{array}{l}\text { Formar uma equipe para li- } \\
\text { dar com o assédio de maneira } \\
\text { coordenada e multidiscipli- } \\
\text { nar. }\end{array}$ & Guimarães; Rimoli (2006). & 1 \\
\hline
\end{tabular}




\begin{tabular}{|c|c|c|}
\hline \multicolumn{3}{|l|}{ INTERVENÇÃO } \\
\hline ITENS $(\mathrm{N}=12)$ & AUTOR(ES) & FREQ. \\
\hline $\begin{array}{l}\text { Possuir conselheiros internos } \\
\text { independentes capazes de } \\
\text { prover informação da política } \\
\text { e dos procedimentos. }\end{array}$ & Tehrani (2005). & 1 \\
\hline $\begin{array}{l}\text { Demonstrar à organização } \\
\text { que o assédio moral é um } \\
\text { fenômeno complexo e que } \\
\text { todos saem perdendo: indiví- } \\
\text { duo, organização e sociedade. }\end{array}$ & Elgenneni (2007.) & 1 \\
\hline $\begin{array}{l}\text { Coibir comportamentos ina- } \\
\text { dequados que conduzam ao } \\
\text { assédio. }\end{array}$ & Avila (2008). & 1 \\
\hline $\begin{array}{l}\text { Ter procedimentos especiais } \\
\text { para casos em que os envol- } \\
\text { vidos são de diferentes níveis } \\
\text { hierárquicos. }\end{array}$ & Scanfone; Teodósio (2004). & 1 \\
\hline $\begin{array}{l}\text { Tornar visível as situações de } \\
\text { assédio moral por parte dos } \\
\text { trabalhadores. }\end{array}$ & Avila (2008). & 1 \\
\hline
\end{tabular}

Fonte: adaptado de Pinheiro e Tolfo (2010) e Fabro e Tolfo (2011)

As propostas de intervenção sugerem a criação de ferramentas que garantam a constitucionalidade no ambiente laboral por meio de normas e regras de proteção e coibição da violência contra os trabalhadores. A criação de comitês e canais de escuta/mediação, normas e regras que definem limites ou sanções aos comportamentos hostis, apoio psicológico ou terapêutico às vítimas, entre outras medidas, também auxiliam no combate à violência e seus efeitos (TOLFO et al., 2016).

As estratégias contra o assédio aqui apresentadas não são inteiramente novas e muitas delas devem (ou deveriam) estar presentes nas práticas cotidianas para que as organizações tenham bom e saudável ambiente - porém, isso geralmente não ocorre. O que é observado muitas vezes é o abismo entre o discurso e a prática. Ou seja, por um lado existe a verbalização da organização sobre o compromisso do bem-estar do trabalhador e de seu posicionamento 
contra qualquer tipo de violência e comportamentos antiéticos e, por outro, ela própria "incentiva" e não coíbe tais práticas, uma vez que geram resultados positivos para ela (NUNES; TOLFO, 2012b; 2015).

\section{Procedimentos metodológicos}

Esta pesquisa tem abordagem qualitativa e descritiva, sendo que o enfoque qualitativo visa responder questões particulares com um grau de realidade que não pode ser quantificado, na medida em que trabalha com vasto universo de significados, motivos, aspirações, valores e atitudes que correspondem a um espaço mais profundo das relações, dos processos e dos fenômenos que não podem ser reduzidos à operacionalização de variáveis (MINAYO et al., 1994; VIEIRA; RIVERA, 2012). Já a dimensão descritiva tem por objetivo principal a descrição das características de determinada população ou fenômeno, além disso, o estabelecimento de relações entre variáveis (GIL, 2007). Assim, como já ressaltado, a investigação descreve a percepção dos servidores docentes e técnico-administrativos sobre o posicionamento e ações de prevenção e combate ao assédio moral de uma universidade federal localizada na região Sul brasileira.

O universo da pesquisa compreendeu 5.714 servidores (3.174 técnicos-administrativos e 2.540 docentes). Não foi definida amostra, uma vez que os pesquisadores tiveram meios de divulgar o questionário online para todos os trabalhadores da universidade. Portanto, a divulgação desta etapa ocorreu majoritariamente por e-mail enviado aos servidores e também pelo próprio sistema de divulgação da universidade. Desse modo a pesquisa pode ser considerada censitária, pois abrange a totalidade dos componentes do universo (MARCONI; LAKATOS, 2009).

Os dados foram coletados com a aplicação de um questionário online (com perguntas abertas) e a realização de entrevistas, que passaram por um pré-teste com docentes, técnicos-administrativos e pós-graduandos com conhecimento sobre a temática. Desse modo se realizou melhor adequação dos instrumentos a partir das argumentações dos sujeitos. Por se tratar de temática delicada, como é o assédio moral, a escolha de disponibilizar o questionário online garantiu maior anonimato, além de ter aumentado o número de participantes na investigação. Dessa forma as questões (abertas) en- 
volvem a relação entre o assédio moral e as práticas da universidade, como o posicionamento da instituição sobre o assédio e medidas de prevenção e combate. Para este trabalho recorreu-se a estudiosos como Nunes (2011); Nunes e Tolfo (2012b), Einarsen e Hoel (2008), Freitas, Heloani e Barreto (2008), Hirigoyen (2006; 2008) e outros autores que analisam a temática.

No final do questionário online constava uma pergunta na qual convidava o respondente a participar de uma entrevista, com objetivo de aprofundar sobre a temática pesquisada. A partir do contato fornecido pelo respondente e análise prévia das respostas do mesmo, ocorreu o agendamento e consequentemente a entrevista. Utilizou-se entrevistas semiestruturadas, seguindo roteiro similar ao do questionário, porém em menor número de questionamentos. O questionário online foi respondido por 214 participantes e desses 12 foram entrevistados. Por questões de anonimato e proteção, os respondentes do questionário foram identificados com a letra " $\mathrm{P}$ " seguidos com seus respectivos números (1 a 214) e os entrevistados com a letra "E" de 1 a 12.

A partir dos dados obtidos no questionário online e nas entrevistas, o passo seguinte deu-se pela análise e interpretação das respostas. (Não entendi. Creio que há muitas informações em uma única frase. Melhor dividi-la,). As informações foram analisadas seguindo abordagem de análise qualitativa. Portanto, foi utilizado a análise de conteúdo que consiste em um conjunto de técnicas de análise das comunicações que visa obter indicadores por meio de procedimentos sistemáticos e objetivos de descrição do conteúdo das mensagens para a inferência de conhecimentos referentes às condições da geração dessas mensagens (BARDIN, 2004). As categorias de análise da pesquisa se desdobram basicamente em dois itens: posicionamento da universidade sobre o assédio moral; estratégias de prevenção e combate ao assédio moral.

Em relação aos participantes da pesquisa, algumas informações se sobressaem. O público feminino teve $53,3 \%$ de participação na pesquisa, o que corresponde a 114 respostas, 15 a mais do que o sexo masculino. No que se refere à faixa etária, a grande maioria $(41,1 \%$ ou 88 respondentes) tem idade entre 25 e 35 anos e quanto ao tempo de serviço, 49,5\% (106) estão na universidade entre 1 e 5 anos. Quan- 
to à formação, $82,2 \%$ (176) têm curso de pós-graduação completo, o que destaca a alta qualificação dos trabalhadores. A maioria dos participantes da pesquisa (116 ou $54,2 \%$ ) compõe-se de servidores técnico-administrativos. O regime de trabalho com maior incidência é o de 40 horas semanais, com 50,9\% (109), seguido por dedicação exclusiva, com 43,9\% (94). Um total de 80,8\% (173) dos respondentes afirmaram não possuírem cargo de direção ou função gratificada.

\section{APRESENTAÇÃo E ANÁlise dOS DADOS}

Os dados a seguir revelam a posição dos participantes da pesquisa em relação às políticas, ações e discursos institucionais sobre o assédio moral no trabalho. Ao contrário das outras pesquisas que apresentam a ocorrência e as características da violência, nesta investigação o foco está na própria universidade e nas suas atividades em relação a tal questão. Por conseguinte, é possível identificar até que ponto a gestão dispõe do tema como algo relevante dentro de suas políticas e práticas institucionais. Em muitas situações é possível identificar que as ações concretas e os discursos organizacionais não estão em pleno alinhamento e ao se considerar o assédio moral o distanciamento é ainda maior (NUNES; TOLFO, 2012b).

Em pesquisa realizada por Nunes e Tolfo (2012b) ficou evidenciado com $47,7 \%$ que a prática de assédio moral é comum no ambiente universitário. Isso corrobora com o ressaltado na tese de Hirigoyen (2006), segundo a qual o meio acadêmico se destaca como um dos mais afetados pela prática de assédio moral. Percebese diante de tais considerações que o ambiente universitário é um espaço limitado e somente "o melhor" poderá alcançar a notoriedade (HIRIGOYEN, 2006), revelando que a busca por poder e o abuso de poder são estratégias comumente utilizadas pelos agressores (NUNES; TOLFO; NUNES, 2013).

Pelo fato de o assédio moral nesta pesquisa ocorrer a partir das relações de trabalho na universidade, há que se enfatizar a responsabilidade da instituição se posicionar em relação à violência (NUNES; TOLFO, 2012b). Contudo este posicionamento muitas vezes fica apenas em um discurso para agradar os trabalhadores, pois a prática pode ser completamente diferente. Ou seja, o discurso é que a universidade se diz contra a violência, o que logicamente é verdade, 
porém na prática ela permite a sua ocorrência por ignorar determinados casos ou os motivos pelos quais as hostilidades ocorrem. Foi questionado aos participantes sobre a sua percepção quanto à clareza do posicionamento da instituição acerca do assédio moral: $43 \%$ afirmaram que o posicionamento não é claro; $26,6 \%$ entendem que ela às vezes deixa claro; $16,8 \%$ que deixa claro e $13,6 \%$ não responderam.

Os participantes enfatizaram que a universidade, por meio das políticas e ações de gestão, não demonstra claramente seu posicionamento frente ao assédio moral (43,0\%). Isso faz que os trabalhadores, que são vítimas da violência, tenham medo de, por exemplo, expor para suas chefias ou aos setores competentes o que estão vivendo dentro do ambiente de trabalho (NUNES; TOLFO, 2013b).

Muitos participantes relataram que desconhecem o posicionamento da universidade sobre o tema (P34; P77; P81; P92; P117; P155; P174; P203) - “Desconheço algum posicionamento central quanto ao assunto, tampouco conheço algum caso de apuração ou sindicância sobre o tema" (P34). Constata-se, segundo eles, que falta mais esclarecimentos e informação: "Penso que deveria esclarecer muito bem os servidores quanto a isso" (P35). Para outros, a própria gestão da universidade não deixa claro o seu posicionamento como uma estratégia política, assim, desta forma ela não tem que agir contra aqueles que "ela defende ou é mais favorável". Tal fato é verificado em um dos discursos: "Não só não toca no assunto, como a própria gestão finge que não sabe que o assédio moral é frequente, principalmente de docentes contra técnicos, como também pratica" (P145). Pode-se inferir, portanto, que "Não há idoneidade no processo" (P32).

Em sequência, 26,6\% dos pesquisados relatam que às vezes a universidade deixa claro seu posicionamento em relação ao assédio moral, conforme se vê a seguir: “Ultimamente é que esta questão vem sendo discutida, mas não está muito clara para as pessoas, porque estas tendem muito a ver o que os outros fazem com ela, e não o contrário" (P26); "Há campanhas combatendo, mas na prática não funciona e o assédio continua ocorrendo, pois a gestão acaba proporcionando um ambiente propício a esta prática, através (sic) de ações coercitivas" (P30); “Vejo uma manifestação por parte do setor de assistência social, mas nunca vi manifestação direta do gabinete da reitoria" (P56). 
Um dos pontos de destaque na interpretação de uma situação de assédio moral está no discurso de P26 “[...] porque estas [as pessoas] tendem muito a ver o que os outros fazem com ela, e não o contrário". Nesse aspecto pode existir a má interpretação de situações como assédio moral em que, por exemplo, um superior hierárquico pode cobrar a assiduidade ou o trabalho bem feito e o trabalhador (que chega atrasado e/ou sai cedo, e não faz suas atividades corretamente) já considera tal ato como assédio (PIÑUEL, 2013; TOLFO; OLIVEIRA, 2013). Em outras palavras, muitos apenas visualizam seus "direitos", mas deixam de lado suas obrigações.

Em contrapartida existe, para alguns, o posicionamento claro da universidade em relação ao assédio moral no trabalho, identificado por $16,8 \%$ dos pesquisados, para os quais ela exerce bem seu papel: "Está bem explicitada a contrariedade da universidade perante o assédio moral no trabalho" (P129); "Há manifestação clara sobre a política institucional [do setor de Gestão de Pessoas] para combater o assédio moral" (P134); "No plano formal a política institucional deixa claro (sic) a não aceitação desse comportamento" (P143).

Nos discursos anteriores de confirmação do posicionamento é facilmente identificado que o entendimento está mais no plano do discurso e da política institucional, principalmente a partir do depoimento de P134 e P143. Apesar de algumas vezes acontecerem situações em que realmente a gestão da universidade se posiciona em relação ao assédio, muito do discurso proferido sobretudo pelos gestores é diferente do que ocorre na prática. Tais situações podem ser confirmadas pelos próprios trabalhadores: "No papel deixa claro, mas na prática acontece diariamente" (P151); “Na teoria temos mecanismos de controle e apuração, mas na prática o que se faz em muitos casos é ignorar e não se indispor com ninguém" (P189); “Só que na prática não funciona; as reclamações são ignoradas" (P214). Existe a diferenciação entre a escrita/discurso e suas ações, que efetivamente demonstram o seu posicionamento em relação a violência. Um dos participantes da pesquisa afirma:

Eu acho que o que se fala de assédio moral é para inglês ver. Por isso que eu acho, eu até fiz questão de participar da pesquisa, que eu acredito que a gente precisa deixar isso bem claro, bem no papel, e 
colocar isso como um argumento mesmo né. Para ir conseguindo mudar as práticas né. Porque se vê que é um discurso de assédio moral como algo muito lindo que está sendo trabalhado, mas na prática tu não vê. Tu vais até o setor e ninguém consegue se sentir protegido e identificado com qualquer lei e regra né. Realmente a gente precisa de mais. Então essa aproximação do discurso e pratica. [...] Aí a gente lê "ai que lindo, é um combate... olha que não pode ser assediado", ai vira pro lado e teu chefe... tipo... Então existe uma distância enorme, um abismo (E3).

Segundo Chanlat (1997), existem dois aspectos em todos os modos de gestão: um abstrato, prescrito, formal e estático (modo de gestão prescrito), e o outro concreto, real, informal e dinâmico (modo de gestão real). Muitas vezes existem contradições entre eles, o que gera um paradoxo e consequentemente inseguranças em relação às formas corretas de agir no ambiente organizacional (CHANLAT, 1997), de modo que um ambiente permissivo tende a ser propício ao assédio moral (TOLFO; NUNES; EMMENDOERFER, 2015; TOLFO; SILVA; KRAWULSKI, 2015).

Em uma perspectiva que inverte a ótica da violência, um dos participantes relata que a universidade "deixa claro que o problema sempre está com o assediado" (P72). E, portanto, essa visão põe o ônus da culpa da violência na própria vítima, descartando assim a perversão do agressor e a sua responsabilidade. Algumas teorias psicanalíticas creditam parte da culpa à vítima, como se de certa forma ela estivesse conivente com o agressor ou desejasse no seu inconsciente a própria situação de agressão, por masoquismo ou por expiação de culpa (HIRIGOYEN, 2008). Freitas, Heloani e Barreto (2008) reforçam esse ponto de vista e acrescentam que em face do interesse de afastar da organização determinadas pessoas, existe uma tendência a responsabilizar o indivíduo assediado pelo surgimento de tais problemas. Com o tempo a própria vítima passa a ter avaliação negativa de si e questiona-se quando pode ter errado e/ou o quê pode ter feito para merecer tal situação, o que constitui mais uma forma perversa de violência (GARCIA; TOLFO, 2011). Ou seja, inverte-se totalmente a responsabilidade das ações hostis perpetradas. 
Os estudos de Leymann (1996) seguem a mesma linha de raciocínio e pontuam que quando o assédio moral se torna oficial os dirigentes organizacionais tendem a culpabilizar a vítima pela violência sofrida e a provocar situações para o seu afastamento do local de trabalho. Heloani (2004) enfatiza que o assédio moral é um fenômeno que envolve interações sociais complexas, e, portanto, as vítimas não devem ser culpadas pela violência.

Um aspecto levantado sobre o posicionamento da instituição quanto ao assédio moral, tendo como base a opinião dos participantes, é que raramente a gestão se posiciona por meio de ações efetivas. Os dados levantados ressaltam a falta de atuação da instituição frente a situações antiéticas e de maus comportamentos e práticas dentro do seu ambiente. No discurso e nas políticas institucionais a teoria é excelente, porém, efetivamente o que interessa e é importante para o trabalhador são ações corretas e efetivas para cessar com estas violências.

Já para Salin (2008) e Nunes, Cugnier e Tolfo (2015) um dos importantes pontos para a redução da violência é a sua divulgação e a informação, ou seja, é fazer com que os trabalhadores compreendam principalmente o que é assédio moral, suas peculiaridades, consequências. Neste aspecto, poucas ações ocorreram e algumas se deram por iniciativas (como cartilhas e atendimento psicológico) de grupos de pesquisa e determinados setores que preenchem um espaço carente de informação e amparo para aqueles que sofrem/ sofreram da violência, porém nenhuma ação mais específica da gestão da universidade, conforme pode ser visualizado nas falas: "São divulgados atendimentos sobre esse tema no e-mail da universidade" (P12); "Desconheço qualquer ação institucional na questão do assédio" (P68); "Até agora, nunca li/recebi nenhum material institucional a respeito do tema" (P195); “Um ou outro informativo é postado, mas não se vê um trabalho in locus. Quem está sendo assediado pode não estar podendo sair e manifestar este assédio" (P198).

Os pesquisadores explicam que em contraposição à ausência de iniciativa por parte da instituição em relação à divulgação do assédio moral no trabalho existem cartilhas e grupos de atendimento psicológico, iniciativas de grupo de extensão/pesquisa da instituição, que preenchem o espaço carente de informação e amparo para aqueles 
que sofrem da violência. Assim como outos estudiosos, na visão de Fabro e Maehler (2015) a prevenção por meio da conscientização e educação dos trabalhadores é uma ferramenta para combater a ocorrência da violência. As estratégias, segundo as autoras, dão-se pela divulgação de forma ampla e qualificada, uma vez que ainda existe um desconhecimento sobre o que é a temática ou também informações muito vagas.

Cabe tanto à organização quanto aos sindicatos acolher, ouvir, apoiar e representar as vítimas de assédio, além de informar os trabalhadores por meio de divulgação de notícias, informativos e palestras sobre a violência (BARRETO, 2006). Assim, ao serem questionados sobre quais ações os dirigentes da instituição podem tomar em relação à prevenção e combate do assédio moral as respostas dos participantes concentraram-se no aspecto individual (comportamento do indivíduo) e também no institucional (ações e estratégias tomadas pela instituição). No individual os principais pronunciamentos foram: "Primeiramente que eles dessem o exemplo e lessem o código de ética, pois se a alta administração não dá o exemplo. Como exigir que os baixos escalões façam diferente?" (P10); "Prestem sempre atenção e escutem seus subordinados; eles podem estar pedindo ajuda em silêncio" (P81); "É necessário que os próprios servidores se conscientizem de que na esfera do trabalho é fundamental que as necessidades prioritárias sejam aquelas institucionais, ao invés das pessoais. Infelizmente estas últimas predominam" (P89).

As declarações englobam diversas situações, mas todas as pessoas focaram no comportamento e nas ações dos trabalhadores. A ação com maior relevância é a prática do código de ética, que já pressupõe diversas condutas que muitas vezes não são observadas pelos trabalhadores da instituição, e isso repercute em ações e comportamentos negativos dentro do ambiente laboral. Esta normalização em questão trata-se do código de ética profissional, especificamente o do servidor público federal, constituído pelo Decreto $\mathrm{n}^{\mathrm{o}}$ 1.171, de 22 de junho de 1994, que dispõe sobre as regras, deveres e obrigações do servidor público (BRASIL, 1994). Mas estudiosos da temática enfatizam que "os códigos de conduta e os códigos de ética não isentam a empresa de suas responsabilidades em casos de assédio moral, especialmente quando outras medidas não foram 
tomadas e/ou a organização foi conivente ou negligente" (FREITAS; HELOANI; BARRETO, 2008, p. 112).

Outro aspecto muito enfatizado é respeitar e valorizar os trabalhadores da instituição (P50; P144; P184; P201). Essa situação não reflete apenas um gênero, uma categoria ou o tempo de instituição, mas repercute em todos os trabalhadores - independentemente das diferenças e peculiaridades de cada um. Ou seja, existem situações mencionadas em que as práticas de assédio moral ocorrem, por exemplo, por uma questão de pertencimento ou não a uma categoria e também pelo tempo de trabalho na instituição. Ao analisarem o tema, Pires e Macêdo (2006, p. 99), esclarecem que o "setor público é percebido como um terreno onde predominam o apadrinhamento político, as relações de favorecimento pessoal e os privilégios que contornam as normas formalmente instituídas". Os autores lembram que, por conseguinte, existe um sentimento de iniquidade e injustiça, além de um abismo entre o discurso e as práticas oficiais. Sabe-se que a valorização e o respeito ao servidor, seja ele qual for, conseguiriam cessar com muitas das situações hostis presentes dentro da instituição. No entanto, mudar esse tipo de comportamento por meio da cultura não é suficiente, uma vez que a universidade é influenciada por práticas e culturas presentes na sociedade brasileira.

Já os aspectos institucionais (ações e estratégias tomadas pela universidade para a prevenção e o combate ao assédio) se relacionam com a formação das chefias, aplicação e controle do código de ética profissional do servidor público, mudança cultural, criação de comissões, maior divulgação sobre o assédio, gestão mais técnica e menos política e diversas outras. Dito com outras palavras, muitas das ações de prevenção e combate apresentadas pelos participantes não envolvem especificamente o tema assédio, como divulgação e normatização, mas as práticas e comportamentos que podem levar à ocorrência da violência. Isso pode ser observado nos testemunhos em sequência: "Caso haja suspeita de interesses pessoais na atuação de algum servidor, que este seja substituído na função" (P2); "Isto exige uma mudança cultural, seria mais diálogo, transparência, objetivos claros e um efetivo planejamento participativo" (P26); "Fiscalizem e supervisionem a aplicação do Código de Ética Profissional do Servidor Público" (P37); “Capacitar chefias, mapear 
e normatizar procedimentos e processos para que não haja "duas formas" de se fazer a mesma coisa (ou que essa forma não mude a cada quatro anos)" (P159). Além desses destacamos também o seguinte depoimento:

Deveria haver uma campanha de mídia, com cartazes, cartilha, e-mails, nas redes sociais e palestras descentralizadas e em grupos menores, além de um formulário online, oficial, para denúncia. Também deveria se divulgar o que pode ocorrer caso o assédio seja comprovado, tanto para o assediador quanto para a instituição. Assim os assediadores ficariam intimidados e o assédio diminuiria (P19).

A criação de comissões fixas para as quais os processos administrativos seriam encaminhados para avaliação, tanto dos casos de alegada falta de cumprimento dos deveres de servidor como (versus) a alegação de assédio moral. Tais comissões fixas deveriam contar com estrutura de profissionais necessários à análise dos casos, como aqueles da Psicologia/Psiquiatria e do Direito, por exemplo. Finalmente - e não desconsiderando que pode haver, sim, casos de assédio moral - que houvesse a aplicação das sanções previstas em lei para os casos em que restasse comprovado não haver assédio moral, caso o servidor usasse dessa alegação para tentar justificar a falta de cumprimento de suas funções (P44).

O testemunho dos participantes, em geral, tem os seguintes direcionamentos: substituição da função para quem direciona suas ações em benefício pessoal/grupal; maior divulgação do assédio (mídias, cartazes, cartilhas, e-mails, redes sociais, palestras); formulário online para denúncia; divulgação dos casos confirmados; mudança cultural (mais diálogo, transparência, objetivos claros e planejamento participativo); mais respeito aos TAE's e pleno conhecimento de suas atividades; fiscalização e supervisão do código de ética profissional do servidor público; criação de comissões fixas (com atuação de profissionais capacitados e de diferentes áreas de atuação) e consequentemente punição para os culpados; capacitar chefias; mapear e normatizar procedimentos e processos (para não ocorrer ambiguidades de entendimentos); gestão mais técnica e menos política. 
Para Tolfo, Nunes e Emmendoerfer (2015), além da utilização do código de ética outras ações podem amenizar a ocorrência da violência, tais como: divulgação de informações para os trabalhadores sobre qualidade de vida e relacionamento interpessoal no trabalho; treinamentos sobre ética, bem como divulgar e informar também as chefias sobre responsabilidade social e assédio moral; preparação dos profissionais de gestão de pessoas para receber denúncias; criação de um canal de comunicação de denúncias por meio do serviço de ombudsman, de comissões de auditoria ou por meio eletrônico; participação/desenvolvimento de congressos, seminários ou palestras sobre o assédio.

Um dos pontos ressaltados no que se refere a essa temática é que alguns tentam se utilizar do tema em proveito próprio, ou seja, o trabalhador alega que está sofrendo assédio moral para justificar a falta de cumprimento de suas atividades laborais (P44). Existe, além da má fé, a falta de conhecimento sobre o assunto. Nesses casos, na visão do entrevistado P44, necessariamente aquele que utiliza essa estratégia deve ser punido. Com a popularização e divulgação do tema nas mídias e em outros meios, cresce também a incompreensão a essa problemática, que pode levar a banalizar e interpretar de maneira incorreta o significado e o alcance do problema (NUNES; TOLFO; ESPINOSA, 2015). Pode ainda servir de ferramenta para trabalhadores usarem maldosamente como forma de garantir a permanência de seu status quo - falta de interesse em trabalhar, por exemplo.

Não há duvida de que esse tipo de violência - assim como todos os outros - é algo sério, principalmente para aquele que sofre as hostilidades. Um importante aspecto é ressaltado por um dos participantes: "Assédio moral é muito sério, desmotiva e adoenta os servidores e isso é responsabilidade da administração. Toda denúncia de assédio moral deve ser investigada e a retirada do servidor do local de trabalho deve ocorrer na hora" (P182). Esta estratégia de fato é relevante para a proteção da vítima, pois ao afastá-la pode-se protegê-la e evitar que as consequências e danos sejam maiores (HIRIGOYEN, 2006; 2008). Oportuno mencionar que a verificação dos casos é lenta e morosa e lamentavelmente o mesmo ocorre com a retirada da vítima do seu local de trabalho, devido 
à grande quantidade de atividades que os trabalhadores exercem e ao déficit numérico de servidores nos setores e departamentos (NUNES, 2011; NUNES; TOLFO, 2013b). Tal dificuldade ocorre sobretudo em se tratando de servidores técnico-administrativos. No caso de docentes, nem sempre é possível a sua retirada do departamento ao qual este está vinculado, uma vez que ele ministra aulas e coordena atividades.

No que se refere à direcionalidade do assédio moral as pesquisas mostram que grande maioria da ocorrência parte do superior hierárquico para o(s) alvo(s) (EINARSEN et al., 2005; 2011; HIRIGOYEN, 2006; FREITAS; HELOANI; BARRETO 2008). O depoimento de servidores corrobora essa informação e revela o comportamento e ações das chefias com os trabalhadores, refletindo a necessidade de melhor capacitar aquelas pessoas que ocupam cargos de direção: "Cuidem do preparo humano das chefias que escolhem" (P95); "Deveriam capacitar as chefias para exercer trabalhos administrativos e na lida com seus servidores" (P124). Ou seja, muitos dos trabalhadores que estão em cargos de chefia não têm preparo para comandar equipes de trabalho e alguns desconhecem suas funções e também a dos seus subordinados e com isso atribuem atividades fora da área de competência dos mesmos, e têm comportamentos desconsoantes com os serviores. Promover melhorias nas relações interpessoais, alterações de comportamentos impróprios e treinamento de funcionários são algumas estratégias listadas por Pinheiro e Tolfo (2010) para prevenir determinados abusos cometidos. Desta forma, educar e capacitar os trabalhadores e principalmente os gestores frente a questões de assédio moral é um dos principais elementos destacados na literatura (PIÑUEL Y ZABALA, 2003; TEHRANI, 2005; BESWICK; GORE; PALFERMAN, 2006; SALIN, 2008; MARTININGO FILHO; SIQUEIRA, 2008).

Por fim, foi possível verificar por meio das falas dos participantes o discurso e as práticas adotadas pela instituição em relação ao seu posicionamento sobre o assédio moral e suas estratégias para divulgar, prevenir e combater. Por conseguinte, constatou-se a existência de grande disparidade entre o que a universidade anuncia e seus reais procedimentos para tratar questão. A instituição efetivamente não demonstra por meio de ações o seu posicionamento 
contra a violência, uma vez que muitos casos não são tratados seriamente, mas à base do discurso.

\section{CONSIDERAÇõES FINAIS}

Ao compreender que o assédio moral também é uma questão organizacional, podemos identificar que algumas organizações ignoram aspectos desencadeadores dessa violência. Ou seja, muitas vezes o assédio moral ocorre porque os gestores se omitem (FREITAS; HELOANI; BARRETO, 2008), geralmente devido ao alcance dos resultados por eles estipulados e/ou pelo desconhecimento da violência (NUNES; TOLFO, 2013a). Embora situações dessa natureza ocorram com muita frequência, é função dos gestores e da própria organização definir estratégias e tomar medidas de prevenção e combate ao assédio moral de forma a garantir um ambiente saudável e bem-estar aos seus trabalhadores. Portanto, este artigo objetivou descrever a percepção dos servidores docentes e técnico-administrativos de uma universidade federal em relação às práticas e discursos organizacionais sobre o assédio moral no trabalho.

Sobre a notoriedade do assédio moral ficou evidenciado que a instituição, por meio de suas políticas e ações, não demonstra ou atua claramente em relação ao assédio moral (43\%). A falta de clareza quanto ao posicionamento da universidade face a prática dessa violência entre seus funcionários pode ser um dos motivos para as vítimas da violência não realizarem a denúncia. Para algumas delas a informação passada pela universidade sobre o tema está voltada mais para um discurso vazio, sem prática efetiva de ação, ou seja, existe uma contradição do que é dito e realizado.

Culturalmente, a sutileza dos discursos institucionais reflete preocupação quanto ao bem-estar e desenvolvimento da sociedade, dos servidores e dos discentes. Todavia, na verdade, por trás desse discurso encontra-se uma diferenciação de categoria e grupos, uma prática de impunidade para aqueles que ultrapassam os limites éticos, o abuso de poder e muitos outros comportamentos e ações que favorecem a criação de um ambiente de conflitos, disputa, divergências e assédio moral. Em consequência disso o trabalhador fica impotente frente a formação de expectativas positivas quanto à 
possibilidade de uma mudança cultural favorável às boas práticas e comportamentos organizacionais e interpessoais dentro do trabalho.

Por sua vez, muitas das estratégias de prevenção e combate propostas pelos participantes vão além de apenas divulgar o assédio moral, por exemplo, mas englobam tanto aspectos relacionados ao próprio indivíduo, seu comportamento e ações no trabalho (como a prática do código de ética, respeitar e valorizar o outro, e outros), quanto institucionais - aspectos culturais e práticas institucionais (formação das chefias, aplicação e controle do código de ética profissional do servidor público, mudança cultural, criação de comissões, maior divulgação sobre o assédio, gestão mais técnica e menos política e diversas outras). Essas estratégias de prevenção e combate não se relacionam apenas com o assédio, mas também com as práticas antiéticas dentro do trabalho, as quais só poderão ser aplicadas se houver interesse dos gestores.

\section{Agradecimentos}

Agradecimentos especiais à Coordenação de Aperfeiçoamento de Pessoal de Nível Superior (CAPES) pelo apoio e financiamento destinado ao projeto a qual este trabalho científico se originou. Bolsista da CAPES - Processo BEX 9426/14-0.

\section{REFERÊNCIAS}

BARDIN, L. Análise de conteúdo. 3. ed. Lisboa: Edições 70, 2004.

BARRETO, M. Assédio Moral: a violência sutil. Análise epidemiológica e psicossocial no trabalho no Brasil. 2005. 188f. Tese (Doutorado em Psicologia) - Programa de Pós-Graduação em Psicologia Social, Pontifícia Universidade Católica, São Paulo, 2005.

BARRETO, M. Violência, saúde e trabalho: uma jornada de humilhações. São Paulo: EDUC, 2006.

BESWICK, J.; GORE, J.; PALFERMAN, D. Bullying at work: A review of the literature. Health and Safety Laboratory, Derbyshire: HSL, 2006.

BRASIL. Decreto n. 1.171, de 22 de junho de 1994. Aprova o Código de Ética Profissional do Servidor Público Civil do Poder Executivo Federal. Lex: Coletânea de Legislação e Jurisprudência, Brasília, 1994. Disponível em: <http://www.planalto.gov.br/ccivil 03/decreto/d1171. htm>. Acesso em: 10 set. 2014.

CARAN, V. C. S. Riscos Psicossociais e Assédio Moral no Contexto Acadêmico. 2007. 188f. Dissertação (Mestrado em Enfermagem) - Programa de Pós-Graduação em Enfermagem Fundamental, Universidade de São Paulo, São Paulo, 2007. 
CHANLAT, J. F. Modos de gestão, saúde e segurança no trabalho. In: DAVEL, E. P. B.; VASCONCELLOS, J. G. M. (Orgs.). “Recursos Humanos" e subjetividade. Petrópolis: Vozes, p. 118-128, 1997.

DEJOURS, C. A banalização da injustiça social. Rio de Janeiro: FGV, 2007.

EINARSEN, S. et al. Workplace Bullying: individual pathology or organizational culture? In: BOWIE, V.; FISCHER, B. S.; COOPER, C. L. (Orgs.). Workplace Violence: issues, trends, strategies. Devon: Willian Publishing, p. 229-247, 2005.

EINARSEN, S.; HOEL, H. Bullying and mistreatment at work: How managers may prevent and manage such problems. In: KINDER, A; HUGHES R.; COOPER; Cary L. (Eds.). Employee well-being support: A workplace resource. New York: John Wiley and Sons Ltd, p. 161-173, 2008.

EINARSEN, S. et al. The concept of bullying and harassment at work: the European tradition. In: EINARSEN, S. et al. (Orgs.). Bullying and Harassment in the Workplace: Developments in Theory, Research, and Practice. London: Taylor \& Francis, p. 3-39, 2011.

FABRO, A. C.; MAEHLER, C. Combate ao assédio moral no trabalho: identificando medidas adotadas pelas organizações sindicais de SC. In: EMMENDOERFER, M. L.; TOLFO, S. R.; NUNES, T. S. (Org.). Assédio moral: em organizações públicas e a (re)ação dos sindicatos. 1. Ed. Curitiba: ed. CRV, p. 215-228, 2015.

FABRO, A. C.; TOLFO, S. R. Assédio moral no trabalho: Identificando na literatura medidas de combate por parte de organizações. Relatório de pesquisa de iniciação científica. PIBIC/ CNPq - BIP/UFSC 2010/2011 [material não publicado], 2011.

FREITAS, M. E.; HELOANI, R.; BARRETO, M. Assédio moral no trabalho. São Paulo: Cengage Learning, 2008.

GARCIA, I. S.; TOLFO, S. R. Assédio moral no trabalho: culpa e vergonha pela humilhação social. Curitiba: Juruá, 2011.

GIL, A. C. Métodos e técnicas de pesquisa social. 5 ed. São Paulo: Atlas, 2007.

HELOANI, R. Assédio moral - um ensaio sobre a expropriação da dignidade no trabalho.

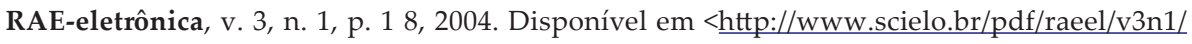

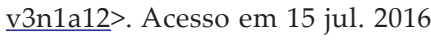

HELOANI, R. Assédio moral: a dignidade violada. Revista Aletheia, Canoas, n. 22, p. 101108, 2005.

HIRIGOYEN, M-F. Assédio moral: a violência perversa no cotidiano. 10. ed. Rio de Janeiro: Bertrand Brasil, 2008.

HIRIGOYEN, M-F. Mal-estar no trabalho: redefinindo o assédio moral. 3. ed. Rio de Janeiro: Bertrand Brasil, 2006.

HOEL, H.; EINARSEN, S.; COOPER, C. L. Organisational effects of bullying. In: EINARSEN, S. et al. (Eds.). Bullying and Emotional Abuse in the Workplace: International perspectives in research and practice. London: Taylor \& Francis, p. 145-162, 2003.

HOEL, H.; SPARKS, K.; COOPER, C. L. The cost of Violence/Stress at work and the benefits of a violence/stress-free working environment. Geneva: Interntational Labour Organisation (ILO), 2001. 
KEASHLY, L.; JAGATIC, K. By any other name: American perspectives on workplace bullying. In: EINARSEN, S. et al. (Eds.). Bullying and Emotional Abuse in the Workplace: International perspectives in research and practice. London: Taylor \& Francis, p. 31-61, 2003.

LEYMANN, H. Mobbing and Psychological Terror at Workplaces. Violence and Victims, v. 5, n. 2, p. 119-126. New York: Springer, 1990.

LEYMANN, H. The Content and Development of Mobbing at Work. European Journal of Work and Organizational Psychology, v.5, n.2, p. 165-184. London: Taylor \& Francis, 1996.

MARCONI, M. A.; LAKATOS, E. M. Metodologia do Trabalho Científico.7. ed. São Paulo: Atlas, 2009.

MARTININGO FILHO, A.; SIQUEIRA, M. V. S. Assédio Moral e Gestão de Pessoas: uma análise do assédio moral nas organizações e o papel da área de gestão de pessoas. Revista de Administração Mackenzie, v. 9, n. 5, p. 11-34, 2008.

MATHISEN, G. E.; EINARSEN, S.; MYKLETUN, R. The relationship between supervisor personality, supervisor's perceived stress and workplace bullying. Journal of Business Ethics, v. 99, n. 4, p. 637-651. 2011.

MINAYO, M. C. S. et al. Pesquisa social: teoria, método e criatividade. Rio de Janeiro: Vozes, 1994.

NUNES, T. S. Assédio moral no trabalho: o contexto dos servidores da Universidade Federal de Santa Catarina. Florianópolis, SC, 2011. 281p. Dissertação (Mestrado) - Universidade Federal de Santa Catarina, Centro Sócio-Econômico. Programa de Pós-Graduação em Administração. Florianópolis, 2011.

NUNES, T. S.; TOLFO, S. R. Assédio moral no trabalho: consequências identificadas por servidores docentes e técnico-administrativos em uma universidade federal brasileira. Revista Gestão Universitária na América Latina - GUAL, Florianópolis, v. 5, n. 3, p. 264-286, 2012a.

NUNES, T. S.; TOLFO, S. R. Políticas y prácticas de prevención y combate al acoso moral en una universidad brasileña. Salud de los Trabajadores, Valência, v. 20, n. 1, p. 61-73, 2012b.

NUNES, T. S.; TOLFO, S. R. A dinâmica e os fatores organizacionais propiciadores à ocorrência do assédio moral no trabalho. Revista de Gestão e Secretariado - GeSec. São Paulo, v. 4, n. 2, p. 90-113, 2013a.

NUNES, T. S.; TOLFO, S. R. Assédio Moral em Universidade: as possíveis consequências em comentar e/ou denunciar a violência. Administração Pública e Gestão Social, v. 5, n. 4, p. 148-155, 2013b.

NUNES, T. S.; TOLFO, S. R. O assédio moral no contexto universitário: uma discussão necessária. Revista de Ciências da Administração, Florianópolis, v. 17, n. 41, p. 21-36, 2015.

NUNES, T. S.; CUGNIER, J. S.; TOLFO, S. R. Prevención y combate al acoso moral en el trabajo: de la información a la acción. In: VILLAR, E. B. et al. (Org.). Hostigamiento Psicológico Laboral e Institucional en Iberoamérica: estado del arte y experiencias de intervención. Buenos Aires: Sb editorial, p. 669-680, 2015. 
NUNES, T. S.; TOLFO, S. R.; ESPINOSA, L. M. C. A compreensão dos trabalhadores sobre o assédio moral no trabalho por meio de um termo/palavra. In: III Congreso Iberoamericano sobre Acoso Laboral e Institucional; IV Seminário Catarinense de Prevenção ao Assédio Moral no Trabalho, 2015, Florianópolis, SC. Anais....., 2015.

NUNES, T. S.; TOLFO, S. R.; NUNES, L. S. Assédio Moral em Universidade: a violência identificada por servidores docentes e técnico-administrativos. Revista Organizações em contexto, São Bernardo do Campo, v. 9, n. 18, p. 25-61, 2013.

PINHEIRO, M. M.; TOLFO, S. R. Prevenção e intervenção do assédio moral no ambiente de trabalho. Relatório de pesquisa de iniciação científica. PIBIC/CNPq, BIP/UFSC. 2010/2011 [material não publicado], 2010.

PIÑUEL, I. Por si acaso te acosan...: 100 cosas que necesitas saber para salir del acoso psicológico en el trabajo. Buenos Aires: Códice, 2013.

PIÑUEL Y ZABALLA, I. Mobbing: como sobreviver ao assédio psicológico no trabalho. São Paulo: Edições Loyola, 2003.

PIRES, J. C. S.; MACÊDO, K. B. Cultura organizacional em organizações públicas no Brasil. Revista de Administração Pública, Rio de Janeiro, v. 40, n. 1, p. 81-105, 2006.

SALIN, D. The prevention of workplace bullying as a question of human resource management: measures adopted and underlying organizational factors. Scandinavian Journal of Management, v. 24, n. 3, p. 221-231, 2008.

SALIN, D. Workplace Bullying among Business Professionals: Prevalence, Organisational Antecedents and Gender Differences. Doctoral dissertation. Research Reports, Serie A, no 117. Helsinki: Swedish School of Economics and Business Administration, 2003.

SKOGSTAD, A. et al. Testing the Work Environment Hypothesis of Bullying on a Group Level of Analysis: Psychosocial Factors as Precursors of Observed Workplace Bullying. Applied Psychology, Oxford, UK, v. 60, n. 3, p. 475-495, 2011.

TEHRANI, N. Bullying at work: beyond policies to a culture of respect. London: CIPD (Chartered Institute of Personnel and Development), 2005.

TOLFO, S. R.; NUNES; T. S.; EMMENDOERFER, M. L. O assédio moral no trabalho e formas de diagnosticar e intervir. In: EMMENDOERFER, M. L.; TOLFO, S. R.; NUNES, T. S. (Orgs.). Assédio moral: em organizações públicas e a (re)ação dos sindicatos. Curitiba, PR: ed. CRV, 2015, p. 243-265.

TOLFO, S. R.; SILVA, N.; KRAWULSKI, E. Assédio moral no trabalho: interface com a cultura organizacional e a gestão de pessoas em organizações públicas. In: EMMENDOERFER, M. L.; TOLFO, S. R.; NUNES, T. S. (Orgs.). Assédio moral: em organizações públicas e a (re) ação dos sindicatos. Curitiba: ed. CRV, p. 99-117, 2015.

TOLFO, S. R. et al. Assédio moral no trabalho: conceitos, aspectos culturais e de gestão de recursos humanos, consequências e possibilidades de intervenção. In: CHAMBEL, M. J. Psicologia da Saúde Ocupacional. Lisboa: ed. Pactor, 259-283, 2016.

TOLFO, S. R.; OLIVEIRA, R. T. Assédio moral no trabalho: uma violência a ser enfrentada. Florianópolis, UFSC, 2013. 
VIEIRA, A. M.; RIVERA, D. P. B. A Hermenêutica no Campo Organizacional: duas possibilidades interpretativistas de pesquisa. Revista Brasileira de Gestão de Negócios, v. 14, n. 44, p. 261-273, 2012.

WARSHAW, L. J. Violence in the workplace. In: STELLMAN, J. M. (Ed.). Enciclopedia de salud y seguridad en el trabajo. Madrid: Ministerio de Trabajo y Asuntos Sociales, 1998. p. 51.1-51.9.

ZIEMER, R. Mitos organizacionais: o poder invisível na vida das empresas. São Paulo: Atlas, 1996.

Recebido em: 02-10-2017

Aprovado em: 17-10-2018

Avaliado pelo sistema double blind review.

Editor: Coordenação do PPGA/UMESP

Disponível em http://mjs.metodista.br/index.php/roc 